\title{
Personalidade patológica
}

\author{
Mayra Silva de Souza - Universidade Federal Fluminense, Niteroi/ RJ, Brasil
}

Caixeta, M., Chaves, M. \& Caixeta, L. (2013). Personalidade patológica. São Paulo: Memnon.

Como o próprio nome sugere, o livro Personalidade Patológica aborda várias temáticas que envolvem os transtornos de personalidade, com posicionamento crítico-reflexivo, ilustrando os temas abordados com casos clínicos. O livro tem 23 capítulos, divididos em 5 grandes partes, quais sejam: 1) Distúrbios de personalidade: conceito, diagnóstico e crítica; 2) Os distúrbios impulsivocondutopáticos da personalidade; 3) As personalidades depressivo-ansiosas, 4) Os transtornos "psicóticos" da personalidade; e 5) A personalidade em outras condições patológicas.

Para introduzir os problemas conceituais dos distúrbios de personalidade, os autores partem de uma definição de Jaspers, concedendo a esses distúrbios um caráter fixo e não fásico, com os sintomas fazendo parte do indivíduo. A personalidade é definida como sendo a concepção que temos resultante da observação do comportamento de um indivíduo, envolvendo seu desempenho afetivo, volitivo, cognitivo, etc. Assim justifica-se porque muitos autores criticam a divisão do DSM-IV em eixo I (distúrbios mentais) e II (desordem de personalidade e do desenvolvimento), pois dessa forma, todas as doenças mentais promovem alterações na personalidade.

Discute-se também o que diferencia os distúrbios de personalidade em relação aos outros transtornos mentais e sugere-se a inclusão de um critério, dentre muitos discutidos e considerados insuficientes, como uma delimitação crítica da concepção de Schneider, na qual o indivíduo com transtorno de personalidade é aquele que faz sofrer a si e à sociedade. Esse critério seria de que quem tem um distúrbio de personalidade tem um padrão permanente de comportamento autolesivo. Mais adiante esse critério também é questionado e considerado inadequado, e uma das falhas apontadas é que esse padrão de comportamento é considerado uma disfuncionalidade social, não conseguindo caracterizar um padrão permanente do comportamento autolesivo.

Um ponto crítico apontado pelos autores é que os traços de personalidade (indivíduos narcisistas, passivo-agressivos, paranoides) frequentemente predispõem ao desenvolvimento de desordens psiquiátricas (narcisistas tornando-se depressivos e obsessivos ficando ansiosos). Nesse caso, o problema não é a personalidade, ela apenas contribuiu para o desenvolvimento da entidade medida. Ressalta-se a atenção dos profissionais de saúde mental para os marcadores anatômicos, eletrofisiológicos e neuroquímicos, com o cuidado de não confundir problemas médicos e morais, trazendo consequências deletérias tanto para o sistema médico, como para o judiciário.

Ainda são abordados temas como a confusão entre doença e caráter, nessa mesma linha de raciocínio, que problemas de ordem moral estariam ligados ao caráter; os problemas diagnósticos dos distúrbios de personalidade apresentando a abordagem dimensional e a abordagem estruturalcategorial, os critérios prototípicos e ideais (aqueles capazes de captar todos os sinais e sintomas nucleares de um dado distúrbio) e os critérios politéticos (aqueles em cuja soma de determinados critérios, quando atingida, obtêm-se o diagnóstico). São apresentados também aspectos críticos dos conceitos psicanalíticos aplicados aos distúrbios de personalidade, tanto do ponto de vista conceitual (restrição aos contingentes relacionais, conflito entre as instâncias psíquicas, dentre outros) quanto da prática (pelo fato de os conceitos não serem validados empiricamente e pela incerteza de que o trabalho psicanalítico possa modificar instâncias estruturais da personalidade, como o temperamento). Essas críticas são ilustradas com um caso clínico. Finalizando a parte 1 do livro, apresenta-se um capítulo sobre temperamento, caráter e distúrbios de personalidade trazendo contribuições dos trabalhos de Cloninger e sua equipe do Centro de Estudos da Personalidade do Departamento de Psiquiatria da Universidade de Saint Louis, que buscam correlacionar temperamento, caráter e personalidade.

A partir da segunda parte do livro, as temáticas vão ficando mais específicas e as discussões e reflexões sobre a delimitação teórica dos transtornos de personalidade, são abordadas pela particularidade de cada transtorno. Dessa forma, a parte 2 fala do distúrbio de personalidade antissocial e distúrbio de personalidade sádica, enfocando problemas conceituais, a personalidade sádica, um caso clínico real pautado num laudo psiquiátrico 
para fins penais, seguido de um estudo psicopatológico do caso, trazendo à luz discussões teóricas separando-se subtópicos por distúrbios/sintomas envolvidos no caso, a saber, distúrbio de personalidade antissocial, paranoia e depressão.

Ainda são abordados os distúrbios de personalidade borderline, com apresentação de um caso clínico e a personalidade narcisista, classificando brevemente subtipos clínicopsicopatológicos de narcisismo como reativo, variante psicopática menor, realista, induzido e defensivo. Em seguida, os autores debatem os distúrbios de personalidade histriônica (histérica), cujo capítulo apresenta seu conceito e patogenia, um caso clínico e a sedução (entendida como um componente psicológico importante $\mathrm{da}$ personalidade histriônica, mas depois essa sedução é apresentada associada ao distúrbio narcisista, ao distúrbio histriônico e ao distúrbio limítrofe). No subtópico distúrbios somatoformes e personalidade histriônica apresenta-se um caso clínico justificando-se a associação do transtorno de personalidade histriônica com sintomas somáticos.

Um próximo capítulo aborda a psicopatologia comparada dos distúrbios de personalidade do tipo borderline, histriônica, antissocial, narcisista e anancástica. $\mathrm{O}$ seguinte trata das relações psicopatológicas entre os distúrbios de personalidade impulsivos, com subtópicos abordando distúrbio de personalidade borderline e a personalidade dependente (incluindo o distúrbio borderline e a perturbação de dependência da personalidade), seguido da apresentação de um caso clínico, discutido depois em termos de psicopatologia, discussão clínico-nosográfica e nota terapêutica. Após, os autores apresentam uma intercorrelação entre os distúrbios de personalidade borderline, antissocial, narcísica e histriônica e problemas nas interações precoces.

A parte 3 traz os critérios e conceituações das personalidades depressivo-ansiosas, começando pela masoquista (autofrustrante), dividindo-a em tipos (narcísico, dependente, paranoide, sexual, altruístico, autoagressivo e factício). Logo se fala da personalidade depressiva, partindo-se de concepções históricas como as de Hipócrates e Kraepelin, e depois de aspectos conceituais, e um subtópico sobre terapêutica é apresentado. A personalidade negativista (passivo-agressiva) é a seguinte e depois o distúrbio de personalidade ansiosa é discutido, com ilustração de 2 casos clínicos.
O próximo capítulo trabalha questões relacionadas ao distúrbio de personalidade obsessivo-compulsivo, trazendo brevemente os critérios do DSM-IV, e discutindo o distúrbio baseado numa perspectiva sociobiológico-evolutiva, partindo do pressuposto que essa pode ser apenas uma forma extrema de variação do comportamento humano, já que vários autores postulam uma abordagem dimensional aos distúrbios de personalidade; há ilustração de dois casos clínicos. Em seguida é exposta uma discussão sobre a possível transição entre o distúrbio de personalidade obsessiva (DPOC) e o distúrbio obsessivo-compulsivo (DOC), na qual se fala o estudo de um caso prototípico com uma amostra de 8 sujeitos de transição entre DPOC e DOC, mas apenas 1 caso desses 8 é apresentado, por ser considerado representativo. Entram em pauta alguns subtópicos, como o distúrbio de personalidade obsessiva e alguns transtornos sexuais, homossexualismo e personalidade obsessiva, associação entre distúrbio erétil e distúrbio de personalidade compulsiva, com relato de 2 casos prototípicos. Questiona-se se a adição sexual pode ser considerada da psicologia ou da psicopatologia, corroborando com a discussão enfatizada em todo o livro sobre o conceito de distúrbios de personalidade (doença ou caráter?), enriquecendo a temática com um caso clínico.

Os chamados transtornos "psicóticos" da personalidade, pelos autores, são citados na parte 4, de maneira que primeiramente é apresentada a personalidade esquizoide, com ilustração de caso clínico, e depois o distúrbio de personalidade esquizotípica. Seguindo, vêm os distúrbios de personalidade paranoide, com relato de 7 casos e alguns comentários sobre estes. Um tópico discutido nesse capítulo é a dificuldade diagnóstica entre transtorno delirante e transtorno de personalidade, com apresentação de caso clínico. $\mathrm{O}$ último capítulo dessa parte fala da personalidade fanática, com apresentação de caso clínico.

A última parte do livro aborda a personalidade em outras condições patológicas, começando pela personalidade nos transtornos alimentares, incluindo a anorexia nervosa tipo restritivo, anorexia nervosa tipo bulímico, bulimia nervosa, o comer compulsivo e o comer em excesso. São apresentados alguns estudos de caso e, depois, estudos empíricos na relação pais-filhos nos distúrbios alimentares e estudo empírico da personalidade dos pais, que são relatos de pesquisas realizadas com as famílias das pessoas com esses distúrbios. Outro capítulo fala da cleptomania, 
trazendo estudo de caso clínico e considerações patogênicas relacionadas à personalidade. Outras condições apresentadas são as personalidades associadas à dependência nicotínica (tabagismo), com apresentação de suas formas clínicas. O próximo tópico discutido é a hipocondria e suas relações com a personalidade, no qual se fala do estado psicopatológico na hipocondria, as suas configurações clínicas, o comportamento, a fenomenologia dos estados hipocondríacos, a hipocondria ligada à esquizofrenia, a hipocondria propriamente dita, apresentação de um caso clínico escoltado por debates sobre a psicopatologia e de discussões nosográfica, psicopatológica, patogênica e terapêutica.

Outro capítulo é destinado ao tratamento farmacológico dos distúrbios de personalidade, seguido do capítulo final sobre personalidades anormais na prática da psicologia médica. Nesse último é abordado o distúrbio de personalidade antissocial, com apresentação de um caso clínico; a psicopatologia da psicopatia, o distúrbio de personalidade borderline com um caso clínico ilustrativo, o distúrbio de personalidade histriônica, distúrbio de personalidade narcísica com caso clínico, a psicogenética do narcisismo, personalidade imaginativa, abúlica e astênica, distúrbio de personalidade evitativo, dependente, esquizoide (com caso clínico apresentado), esquizotípico, paranoide, obsessiva (anacástica, compulsiva), passivo-agressivo, sádica (com caso clínico), masoquista e do tipo fanático. Segue-se com a apresentação de um caso clínico ilustrativo do diagnóstico dos transtornos de personalidade, na qual são expostas diversas hipóteses diagnósticas, e uma abordagem crítica das explicações para os transtornos de personalidade, adotando as abordagens: psicanalítica, teorias genéticoconstitucionais, teorias da patologia mental e as teorias cognitivo-comportamentais como alvos de questionamentos.

O livro é em essência muito interessante, trazendo reflexões baseadas tanto nas concepções teóricas, quanto nas práticas. As ilustrações com casos clínicos aproximam o leitor do assunto e do entendimento às críticas feitas às concepções teóricas. $\mathrm{O}$ número grande de capítulos e subtópicos ajuda na dinamização da leitura, de forma que ela não se torna cansativa. Para os interessados em personalidade, em transtornos da personalidade e até mesmo em transtornos mentais no geral, o livro traz discussões interessantes. Vale a pena conferir!

Sobre a autora:

Mayra Silva de Souza é psicóloga, doutora em Psicologia pela Universidade São Francisco e professora adjunta da Universidade Federal Fluminense.

Contato com a autora:

E-mail:mayrass@id.uff.br 